\title{
Theoretical assessment of bonaccordite formation in Pressurized Water Reactors
}

\author{
Zs. Rak ${ }^{1}$, C.J. O’Brien ${ }^{1 \#}$, D. Shin $^{2}$, A.D. Andersson ${ }^{3}$, C. R. Stanek ${ }^{4}$, D.W. \\ Brenner ${ }^{1}$ \\ ${ }^{1}$ Department of Materials Science and Engineering, North Carolina State \\ University, Raleigh, NC 27695 \\ ${ }^{2}$ Materials Science and Technology Division, Oak Ridge National Laboratory, \\ Oak Ridge, TN 37831-6063, \\ ${ }^{3}$ Materials Science and Technology Division, Los Alamos National Laboratory \\ P.O. Box 1663, Los Alamos, NM 87545, \\ \# Current Address: Sandia National Laboratories, Albuquerque, NM 87185
}

\begin{abstract}
The free energy of formation of bonaccordite $\left(\mathrm{Ni}_{2} \mathrm{FeBO}_{5}\right)$ as a function of temperature has been calculated using a technique that combines first principles calculations with experimental free energies of formation of aqueous species. The results suggest that bonaccordite formation from aqueous metal ions $\left(\mathrm{Ni}^{2+}\right.$ and $\left.\mathrm{Fe}^{3+}\right)$ and boric acid is thermodynamically favorable at elevated temperature and $p H$ that have been predicted to exist at the CRUD-clad interface in deposits thicker than $60 \mu \mathrm{m}$.
\end{abstract}


Bonaccordite $\left(\mathrm{Ni}_{2} \mathrm{FeBO}_{5}\right)$ is a member of the Ludwigite mineral group with form $M_{2}^{2+} T^{3+} \mathrm{O}_{2} \mathrm{BO}_{3}$ ( $M, T$ - transition metals). It has only been found in nature in the Bon Accord region of South Africa [1], and it is inadvertently produced in the cores of highduty pressurized light-water nuclear reactors (PWRs) [2]. Bonaccordite has been synthesized by annealing $\mathrm{NiO}, \mathrm{Fe}_{2} \mathrm{O}_{3}$ and boric acid at $1050{ }^{\circ} \mathrm{C}$ followed by slow cooling [3], and by hydrothermal synthesis starting at temperatures above $350^{\circ} \mathrm{C}$ [4].

High-duty PWRs may experience a CRUD Induced Power Shift (CIPS) [5, 6] caused by boron build-up within porous metal oxides that deposit on the fuel cladding in the highest temperature core region. These deposits are referred to as CRUD, an acronym for Chalk River Unidentified Deposits, after the facility at which they were first observed. The deposited boron reduces neutron flux by absorbing neutrons followed by transmutation to lithium. The reduction in thermal neutron flux makes it difficult to achieve high fuel burn-up.

Despite the correlation between bonaccordite in CRUD and plants experiencing CIPS [2, 7], consideration of bonaccordite is missing from CRUD deposition models [5, $6,8,9]$. This is partly due to the lack of experimental thermochemical data for forming this mineral. In addition, hydrothermal synthesis experiments [4] have only shown bonaccordite formation at temperatures above $350{ }^{\circ} \mathrm{C}$, which is higher than PWR coolant temperatures $\left(\sim 315-320{ }^{\circ} \mathrm{C}\right)$. Hence, bonaccordite formation in bulk coolant is unlikely under normal operating conditions. Based on recent CRUD chemistry models (CCMs) [5, 6], however, conditions at the bottom of thick CRUD may be extreme enough for bonaccordite precipitation. According to the CCM model [6] the temperature at the CRUD-clad interface increases with CRUD thickness, reaching $387^{\circ} \mathrm{C}$ at the bottom of a $60 \mu \mathrm{m}$ thick deposit at the beginning of the fuel cycle. Likewise, the $p H$ at the CRUDclad interface is generally higher than in the coolant and its value increases from $\sim 7.6$ to $\sim 8.4$ during the operating fuel cycle for $60 \mu \mathrm{m}$ thick CRUD.

In this paper we calculate the Gibbs free energies of several reactions that can lead to bonaccordite precipitation under calculated conditions present at the CRUD-clad interface in thick CRUD. Because the CCM predicts CRUD regions in contact with the clad to be significantly oxidizing [6], both aqueous $\mathrm{Fe}^{2+}$ and $\mathrm{Fe}^{3+}$ are considered as iron sources for bonaccordite formation.

The Gibbs free energy change for a reaction indicates whether the reaction proceeds spontaneously. To evaluate the possibility of bonaccordite formation in deep CRUD, the following reactions are considered:

$$
\begin{gathered}
2 \mathrm{Ni}_{a q}^{2+}+\mathrm{Fe}_{a q}^{2+}+\left(\mathrm{H}_{3} \mathrm{BO}_{3}\right)_{a q}+2 \mathrm{H}_{2} \mathrm{O} \rightarrow\left(\mathrm{Ni}_{2} \mathrm{FeBO}_{5}\right)_{\text {solid }}+6 \mathrm{H}_{a q}^{+}+\frac{1}{2}\left(\mathrm{H}_{2}\right)_{g a s} \\
2 \mathrm{Ni}_{a q}^{2+}+\mathrm{Fe}_{a q}^{2+}+\left(\mathrm{H}_{3} \mathrm{BO}_{3}\right)_{a q}+2 \mathrm{OH}_{a q}^{-} \rightarrow\left(\mathrm{Ni}_{2} \mathrm{FeBO}_{5}\right)_{\text {solid }}+4 \mathrm{H}_{a q}^{+}+\frac{1}{2}\left(\mathrm{H}_{2}\right)_{g a s} \\
2 \mathrm{Ni}_{a q}^{2+}+\mathrm{Fe}_{a q}^{3+}+\left(\mathrm{H}_{3} \mathrm{BO}_{3}\right)_{a q}+2 \mathrm{H}_{2} \mathrm{O} \rightarrow\left(\mathrm{Ni}_{2} \mathrm{FeBO}_{5}\right)_{\text {solid }}+7 \mathrm{H}_{a q}^{+} \\
2 \mathrm{Ni}_{a q}^{2+}+\mathrm{Fe}_{a q}^{3+}+\left(\mathrm{H}_{3} \mathrm{BO}_{3}\right)_{a q}+2 \mathrm{OH}_{a q}^{-} \rightarrow\left(\mathrm{Ni}_{2} \mathrm{FeBO}_{5}\right)_{\text {solid }}+5 \mathrm{H}_{a q}^{+}
\end{gathered}
$$

To calculate the free energy change for these reactions it is necessary to evaluate the chemical potentials of the aqueous cations $\left(N i_{a q}^{2+}, F e_{a q}^{2+}, F e_{a q}^{3+}\right)$ and dissolved species 
$\left(\left(\mathrm{H}_{3} \mathrm{BO}_{3}\right)_{a q}\right)$ participating in the reactions as well as the chemical potential of solid bonaccordite. Because water molecules and hydroxyl ions are also involved in formation reactions, their chemical potentials have to be determined. As described below, terms involving aqueous proton $\left(\mathrm{H}_{a q}^{+}\right)$and dissolved hydrogen $\left(\left(\mathrm{H}_{2}\right)_{g a s}\right)$ appear explicitly in the expressions of standard chemical potentials of aqueous cations and other dissolved species, and they cancel out during the Gibbs free energy calculations for reactions (1)(4). Therefore, the standard chemical potentials of $H_{a q}^{+}$and $\left(H_{2}\right)_{g a s}$ are not required.

Chemical potentials $\mu_{i}$ for solvated species are given by

$$
\mu_{i}=\mu_{i}^{0}+R T \ln a_{i}
$$

where $\mu_{i}^{0}$ is a standard state potential, $\mathrm{R}$ is the gas constant, $T$ is temperature, and $a_{i}$ is activity in the aqueous solution. Because bonaccordite is weakly soluble in water and the solution is dilute, the activities of aqueous cations and dissolved species are approximated by their concentrations and the water activity is taken as unity.

Standard chemical potentials of the aqueous cations $\left(\mathrm{Ni}_{a q}^{2+}, F e_{a q}^{2+}, F e_{a q}^{3+}\right)$ can be evaluated by combining thermochemical data with total energies calculated by Density Functional Theory (DFT)[10]:

$$
\mu_{M^{z+}, a q}^{0}=\Delta G_{f}^{0}\left(M^{z+}, a q\right)+\mu_{M, \text { solid }}^{0}+z \mu_{H^{+}, a q}^{0}-\frac{z}{2} \mu_{H_{2}, \text { gas }}^{0} .
$$

Gibbs energies of formation, $\Delta G_{f}^{0}$, required for eq. (6) are obtained from the SUPCRT database [11-13]. Coolant pressure is assumed to be 155 bar. The elemental phase chemical potentials $\mu_{M, \text { solid }}^{0}$ are calculated using the DFT-based approach described in [10] (the values used in the present study are listed in the Appendix of [10]).

The standard chemical potentials of dissolved boric acid, hydroxyl ion, and water are expressed using the reactions $B_{\text {solid }}+3 / 2\left(\mathrm{H}_{2}\right)_{\text {gas }}+3 / 2\left(\mathrm{O}_{2}\right)_{\text {gas }} \rightarrow\left(\mathrm{H}_{3} \mathrm{BO}_{3}\right)_{a q}$, $\left(\mathrm{H}_{2}\right)_{\text {gas }}+1 / 2\left(\mathrm{O}_{2}\right)_{\text {gas }} \rightarrow \mathrm{OH}_{a q}^{-}+\mathrm{H}_{a q}^{+}$, and $\left(\mathrm{H}_{2}\right)_{\text {gas }}+1 / 2\left(\mathrm{O}_{2}\right)_{\text {gas }} \rightarrow \mathrm{H}_{2} \mathrm{O}$ respectively, with the chemical potentials of boron and oxygen taken from Ref. [10] and the Gibbs free energies of formation taken from the SUPCRT database.

The chemical potential of solid bonaccordite is obtained from DFT total energy calculations using PAW pseudopotentials [14] and the generalized gradient approximation (GGA) [15] as implemented in VASP [16-19]. Because of the localized nature of $\mathrm{Fe}$ and $\mathrm{Ni} d$-states, orbital-dependent Coulomb interactions were added to the Hamiltonian through the DFT $+U$ method in a rotationally-invariant formulation [20]. Values of $U_{\text {eff }}(\mathrm{Fe})=4.5 U_{\text {eff }}(\mathrm{Ni})=6.0 \mathrm{eV}$ were used because they reproduce well the experimental free energies of formation of $\mathrm{NiO}$ and $\mathrm{NiFe}_{2} \mathrm{O}_{4}$ [10]. The chemical potential of solid bonaccordite is considered to be independent of temperature.

To calculate Gibbs free energies associated with reactions (1)-(4), the concentrations of dissolved species in solution are needed. To be consistent with conditions that could be present at the bottom of thick CRUD, we use concentrations predicted by the CCM model described in [6]. As the coolant chemistry changes 
throughout the operation cycle, we calculate the Gibbs free energies of bonaccordite formation using concentrations from the beginning and end of the cycle (Table I).

Because of lack of information regarding the evolution of $\left[\mathrm{Fe}^{2+}\right]$ and $\left[\mathrm{Ni}^{2+}\right]$ at the CRUD-clad interface, we consider them to be unchanged throughout the fuel cycle. Likewise, because the end-of-cycle values of $\left[\mathrm{H}_{3} \mathrm{BO}_{3}\right]$ and $\left[\mathrm{H}_{2}\right]$ at the bottom of the CRUD are not specified in [6], they are taken equal to the concentrations in the bulk coolant. The beginning-of-cycle value for the concentration of boric acid solution at the bottom of CRUD is predicted as $\sim 6.00 \mathrm{M}$ by the CCM [6], which is approximately 60 times larger than the value in the bulk coolant $(\sim 1800 \mathrm{ppm}$ or $\sim 0.1 \mathrm{M})$. The dissolved proton concentration $\left(\left[H^{+}\right]\right)$is related to $p H$ by $p H=-\log \left[H^{+}\right]$and is taken as a parameter. The values of $\left[\mathrm{H}^{+}\right]$and $\left[\mathrm{OH}^{-}\right]$are constrained by the ionization constant of water, $p K_{w}=-\log \left(\left[H^{+}\right]\left[O H^{-}\right]\right)$. Using a semi-empirical equation [21], $p K_{w}$ is calculated for a temperature range of 25 to $300{ }^{\circ} \mathrm{C}$ and it is combined with $p H=-\log \left[\mathrm{H}^{+}\right]$to obtain the hydroxyl concentration as $\left[\mathrm{OH}^{-}\right]=10^{p H-p K_{w}}$. At the CRUD-clad interface the concentration of oxidizing species reaches significant levels ( $\left[\mathrm{H}_{2} \mathrm{O}_{2}\right]=6.73 \times 10^{-7}$ and $[\mathrm{OH}]=2.52 \times 10^{-10}$ moles $/ \mathrm{dm}^{3}$ ), hence $\mathrm{Fe}^{3+}$ is considered as a source of iron for bonaccordite formation. Both $\mathrm{H}_{2} \mathrm{O}_{2}$ and $\mathrm{OH}$ are the results of radiolysis reaction of water that is taken into account in the CCM calculation [6]. The concentrations of $\mathrm{H}_{2} \mathrm{O}_{2}$ and $\mathrm{OH}$ increases because the steam that passes through the boiling chimneys of the deposit strips $H_{2}$ out of the water at the bottom of CRUD. The $\mathrm{Fe}^{3+}$ concentration is approximated by considering oxidation of $\mathrm{Fe}^{2+}$ :

$$
2 \mathrm{Fe}_{a q}^{2+}+\mathrm{H}_{2} \mathrm{O}_{2}+2 \mathrm{H}_{a q}^{+} \rightarrow 2 \mathrm{Fe}_{a q}^{3+}+2 \mathrm{H}_{2} \mathrm{O}
$$

The calculated $\mathrm{Fe}^{3+}$ concentrations at $325^{\circ} \mathrm{C}$ are listed in Table I. $\left[\mathrm{Fe}^{3+}\right]$ is 5-6 orders of magnitude less than $\left[\mathrm{Fe}^{2+}\right]$ and it decreases toward the end of the cycles because the environment within the porous CRUD becomes less oxidizing.

Using the method specified above with the values in Table I, the free energies of bonaccordite formation are calculated as a function of temperature and plotted in Fig. 1. The free energies decrease with temperature suggesting that bonaccordite precipitation is favorable at higher temperatures, as observed experimentally. There is also a small decrease in formation energies toward the end of the fuel cycle (dashed line in Fig. 1). This drop is more noticeable for reactions (3) and (4), and is due to the $\mathrm{pH}$ increase at the CRUD-clad interface during the fuel cycle. For reactions (1) and (2) this is counterbalanced by the increase in dissolved hydrogen concentration $\left(\left[\mathrm{H}_{2}\right]\right)$, resulting in formation energies that are nearly unchanged throughout the cycle.

An important result of the present study, as illustrated in Fig. 1, is that at temperatures higher than $300{ }^{\circ} \mathrm{C}$ the change in Gibbs free energy associated with reaction (4) becomes negative, predicting thermodynamically stable bonaccordite. Even assuming a relatively large uncertainty in the calculations (e.g. choice of Hubbard $U$, cation 
disorder and magnetic ordering in bonaccordite, solute concentrations predicted by $\mathrm{CCM}$ ), the trend in the calculated formation energies suggests that at higher temperature $\left(>350{ }^{\circ} \mathrm{C}\right)$ bonaccordite would be thermodynamically stable. This agrees with the experimental findings of Sawicki [2,4] that high temperature and thick CRUD are needed for bonaccordite formation in PWRs.

For comparison, the free energies are also calculated using concentrations that are typically measured in the bulk coolant of nuclear plants. These values are listed in Table I and the calculated free energies versus temperature are plotted in Fig. 2. As expected, the positive free energies indicate that under conditions characteristic to bulk coolant, bonaccordite formation is energetically unfavorable,

An additional feature of bonaccordite thermodynamics revealed by the present model is that although the concentration of $\mathrm{Fe}^{3+}$ is 5-6 orders of magnitude smaller than that of $\mathrm{Fe}^{2+}$, bonaccordite formation is thermodynamically more favorable if the $\mathrm{Fe}$ source is $\mathrm{Fe}^{3+}$. This strongly suggests that in future CRUD chemistry and boron deposition models the presence of $\mathrm{Fe}^{3+}$ should be considered in addition to $\mathrm{Fe}^{2+}$.

This study makes the first prediction of the Gibbs standard free energy of formation of bonaccordite and examines the thermodynamics of possible pathways to its formation in PWR environments. The results suggest that bonaccordite formation from aqueous metal ions and boric acid is thermodynamically favorable at conditions predicted to exist at the CRUD-clad interface in deposits thicker than $60 \mu \mathrm{m}$. The results of this study offer key data that are missing in current CRUD deposition models and should be incorporated in future engineering scale simulations.

Table I. Concentrations of dissolved species present at the CRUD-clad interface in a 60 $\mu \mathrm{m}$ thick CRUD at the beginning and the end of the fuel cycle. The third column contains concentrations that are typically measured in the coolant of PWRs. All values are given in moles $/ \mathrm{dm}^{3}$.

\begin{tabular}{llll}
\hline Species & Beginning of cycle & End of cycle & Bulk coolant \\
\hline$p H$ & 7.6 & 8.4 & 7.14 \\
$\mathrm{Fe}^{2+}$ & $4.17 \times 10^{-13}$ & $4.17 \times 10^{-13}$ & $1.40 \times 10^{-8}(\sim 1 \mathrm{ppb})$ \\
$\mathrm{Fe}^{3+}$ & $3.59 \times 10^{-18}$ & $2.91 \times 10^{-19}$ & - \\
$\mathrm{Ni}^{2+}$ & $1.66 \times 10^{-14}$ & $1.66 \times 10^{-14}$ & $0.14 \times 10^{-8}(\sim 0.1 \mathrm{ppb})$ \\
$\mathrm{H}_{3} \mathrm{BO}_{3}$ & 6.00 & $4.82 \times 10^{-4}(\sim 50 \mathrm{ppm})$ & $1.80 \times 10^{-2}(\sim 1800 \mathrm{ppb})$ \\
$\mathrm{H}_{2}$ & $2.96 \times 10^{-5}(\sim 100 \mathrm{ppb})$ & $5.91 \times 10^{-4}(\sim 2 \mathrm{ppm})$ & $5.91 \times 10^{-4}(\sim 2 \mathrm{ppm})$ \\
$\mathrm{H}_{2} \mathrm{O}_{2}$ & $6.73 \times 10^{-7}(\sim 38.4 \mathrm{ppm})$ & $1.75 \times 10^{-7}(\sim 10 \mathrm{ppb})$ & - \\
\hline
\end{tabular}




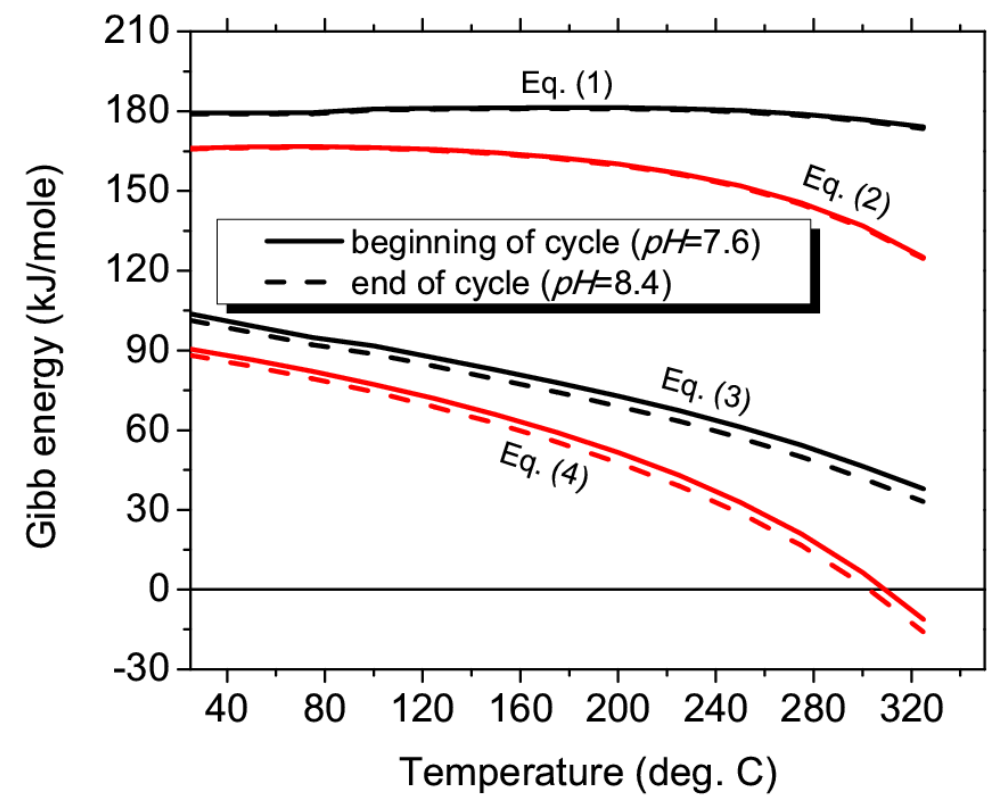

Figure 1. Gibbs free energies of formation of bonaccordite as a function of temperature, for reactions (1)-(4), using concentrations that are predicted to be present at the CRUDclad interface at the bottom of a $60 \mu \mathrm{m}$ thick CRUD.

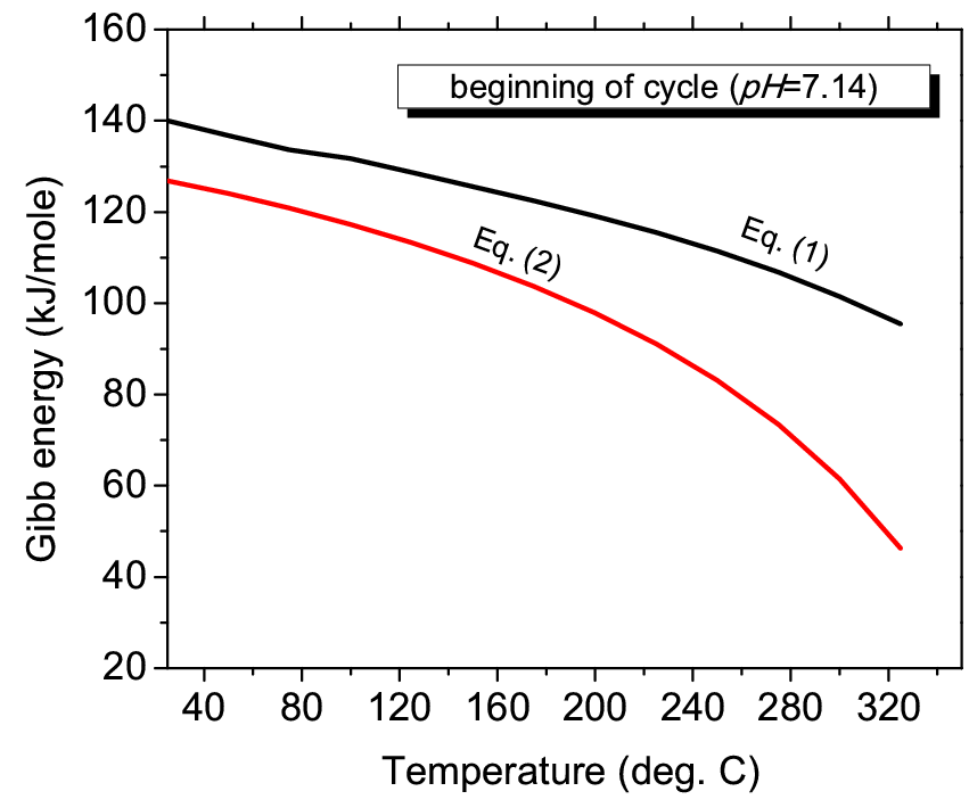

Figure 2. Gibbs free energies of formation of bonaccordite as a function of temperature, using concentrations that are typically measured in nuclear plants. 


\section{Acknowledgements}

This research was supported by the Consortium for Advanced Simulation of Light Water Reactors (http://www.casl.gov), an Energy Innovation Hub (http://www.energy.gov/hubs) for Modeling and Simulation of Nuclear Reactors under U.S. Department of Energy Contract No. DE-AC05-00OR22725

\section{References}

[1] S.A. De Waal, E.A. Viljoen, L.C. Calk, Transactions of the Geological Society of South Africa, 77 (1974) 375.

[2] J.A. Sawicki, Journal of Nuclear Materials, 374 (2008) 248-269.

[3] J.C. Fernandes, R.B. Guimaraes, M.A. Continentino, H.A. Borges, A. Sulpice, J.L. Tholence, J.L. Siqueira, L.I. Zawislak, J.B.M. da Cunha, C.A. dos Santos, Phys Rev B, 58 (1998) 287-292.

[4] J.A. Sawicki, Journal of Nuclear Materials, 415 (2011) 179-188.

[5] J. Henshaw, J.C. McGurk, H.E. Sims, A. Tuson, S. Dickinson, J. Deshon, Journal of Nuclear Materials, 353 (2006) 1-11.

[6] EPRI Report, Palo Alto, CA: 1011743., EPRI Report, Palo Alto, CA, 2005.

[7] J.A. Sawicki, Journal of Nuclear Materials, 402 (2010) 124-129.

[8] I.U. Haq, N. Cinosi, M. Bluck, G. Hewitt, S. Walker, Nucl Eng Des, 241 (2011) 155-162.

[9] J. Deshon, D. Hussey, B. Kendrick, J. McGurk, J. Secker, M. Short, Jom-Us, 63 (2011) 68-76.

[10] Z. Rak, E.W. Bucholz, D.W. Brenner, Journal of Nuclear Materials, 461 (2015) 350-356.

[11] T. Windman, T. Windman, E. Shock, Geochim Cosmochim Ac, 72 (2008) A1027-A1027.

[12] J.W. Johnson, E.H. Oelkers, H.C. Helgeson, Comput Geosci, 18 (1992) 899-947.

[13] J.C. Tanger, H.C. Helgeson, Am J Sci, 288 (1988) 19-98.

[14] P.E. Blochl, Phys Rev B, 50 (1994) 17953-17979.

[15] J.P. Perdew, K. Burke, M. Ernzerhof, Phys Rev Lett, 77 (1996) 3865-3868.

[16] G. Kresse, J. Furthmuller, Phys Rev B, 54 (1996) 11169-11186.

[17] G. Kresse, J. Furthmuller, Computational Materials Science, 6 (1996) 15-50.

[18] G. Kresse, J. Hafner, Phys Rev B, 47 (1993) 558-561.

[19] G. Kresse, J. Hafner, Phys Rev B, 49 (1994) 14251-14269.

[20] S.L. Dudarev, G.A. Botton, S.Y. Savrasov, C.J. Humphreys, A.P. Sutton, Phys Rev B, 57 (1998) 1505-1509.

[21] A.V. Bandura, S.N. Lvov, J Phys Chem Ref Data, 35 (2006) 15-30. 